\title{
DESAIN INSTRUKSIONAL LITERASI INFORMASI MENGGUNAKAN \\ MODEL I-LEARN DI PERPUSTAKAAN UNIVERSITAS YARSI
}

\author{
Elfitri Kurnia Erza, Indah Kurnianingsih, Fitri Risalatul \\ Hafifah \\ Program Studi Perpustakaan dan Sains Informasi, Fakultas \\ Teknologi Informasi, Universitas YARSI \\ elfitri.kurnia@yarsi.ac.id; indah.kurnianingsih@yarsi.ac.id; \\ fitririsalatul39@gmail.com
}

\begin{abstract}
ABSTRAK
Program literasi informasi merupakan salah satu kegiatan yang sangat diperlukan di Perpustakaan Perguruan Tinggi. Tujuan penelitian ini adalah untuk mengetahui karakteristik dan kebutuhan mahasiswa untuk kegiatan literasi informasi serta membuat desain instruksional menggunakan model I-Learn. Model I-LEARN terdiri dari beberapa aspek yaitu identify, locate, evaluate, apply, reflect, dan know. Metode penelitian menggunakan kuantitatif dan kualitatif. Sampel dalam penelitian berjumlah 359 mahasiswa Universitas YARSI. Pengumpulan data primer dilakukan dengan wawancara kepala perpustakaan dan kuesioner. Desain Instruksional menggunakan Model I-LEARN untuk perpustakaan Universitas YARSI terdiri dari (1) identify, perpustakaan dapat membuat program pelatihan mind mapping; (2) locate, perpustakaan dapat melaksanakan seminar dan pelatihan akses informasi, pemilihan sumber informasi, dan seminar dan pelatihan subjek pencarian; (3) evaluate, program seminar evaluasi informasi; (4) apply, program pelatihan aplikasi reference manager dan pelatihan infografis; (5) reflect, perpustakaan dapat menyelenggarakan program seminar anti plagiarisme dan layanan pengecekan plagiarisme; dan (5) know, menyelenggarakan program pengenalan publikasi jurnal \& media online dan menyediakan layanan konsultasi publikasi ilmiah.
\end{abstract}

Kata Kunci: desain instruksional, literasi informasi, model ILearn, perpustakaan Universitas YARSI

\begin{abstract}
Information literacy program is one activities in the University Libraries. The purpose of this research to determine the characteristics and needs of students for information literacy activities and to make instructional designs using the I-Learn model. The I-LEARN model consists of several aspects, indeed identify, locate, evaluate, apply, reflect, and know. The research methode uses quantitative and qualitative. The sample in this research amount to 359 students of YARSI University. Primary data collect by interviewing the head of the library and questionnaires. Instructional design using the I-LEARN Model for the YARSI University library
\end{abstract}


consists of (1) identify, the library can create a mind mapping training program; (2) locate, the library can carry out information access seminars and training, selection of information sources, and search seminars and training; (3) evaluate, information evaluation seminar program; (4) apply, reference manager application training program and infographic training; (5) reflect, the library can organize anti-plagiarism seminar programs and plagiarism checking services; and (5) know, organizing journal publication introduction programs $\&$ online media and providing scientific publication consulting services.

Keywords: instructional design, information literacy, I-Learn Model, YARSI University library 


\section{PENDAHULUAN}

Keberadaan perpustakaan perguruan tinggi pada era digital ini tidak hanya mengelola sumber informasi cetak dan non cetak saja. Namun, perpustakaan sudah mendapatkan tuntutan baru yaitu menjadi fasilitator dalam pembelajaran sepanjang hayat (Mubasyaroh, 2016). Pelaksanaan fungsi ini menyesuaikan dengan Unesco (2007) bahwa masyarakat yang literate tidak hanya mampu membaca dan menulis, namun juga mampu memahami dan menjelaskan informasi yang dibaca dan ditulis. Hal inilah yang kemudian menjadi landasan konsep long life learning (pembelajaran sepanjang hayat). Pelaksanaan konsep ini diperjelas dengan adanya literasi informasi.

Bagi perpustakaan di perguruan tinggi, konsep literasi informasi merupakan hal yang sangat penting. Dalam lingkup literasi informasi fungsi perpustakaan adalah menjadi fasilitator dalam pembelajaran sepanjang hayat. Kemampuan literasi informasi yaitu mampu mengetahui kebutuhan informasi, mengetahui lokasi dan akses sumber informasi, mengetahui bagaimana cara mengakses sumber informasi, menggunakan informasi dengan baik, mengevaluasi informasi yang dipercaya sampai pada mempresentasikan informasi dengan benar. Hal ini menuntut perpustakaan tidak hanya mengelola sumber informasi namun juga menjadi sarana pembelajaran dengan program literasi informasi.

Program literasi informasi merupakan pembekalan yang diberikan perpustakaan kepada pemustaka untuk dapat belajar dengan baik dan benar dan tujuan akhirnya adalah dapat menunjang penggunaan berbagai sumber informasi dalam pembuatan tugas. Adanya kemampuan literasi informasi memungkinkan mahasiswa untuk:

1. Mampu merumuskan/mengetahui/menjelaskan rumusan masalah apa yang dibutuhkan 
2. Mampu menentukan sumber informasi apa saja yang akan digunakan dalam membahas masalah yang diperlukan tersebut

3. Mampu mengetahui lokasi dimana saja sumber informasi tersebut berada dan mengetahui bagaimana cara mengaksesnya.

4. Mampu menggunakan informasi yang didapatkan dengan benar, mengutip dengan cara yang benar, tidak melakukan tindakan plagiarisme dan kesadaran untuk selalu membuat sumber informasi yang digunakan dengan menggunakan gaya sitasi tertentu

5. Mampu mengevaluasi setiap informasi yang didapatkan dan digunakan

6. Mampu mempresentasikan hasil pemikiran, tulisan, dan berbagai informasi di berbagai media.

Menurut Lau (20006) literasi informasi merupakan kemampuan individu dalam memanfaatkan dan menggunakan informasi agar lebih terarah dalam memanfaatkan sumber infomasi dalam kehidupan sehari. Selain itu Lau (2006) menyebutkan komponen yang harus dimiliki dalam mengembangkan kemampuan literasi informasi, yaitu sebagai berikut:

1. Mengakses informasi, pengguna dapat mengakses informasi secara efektif dan efisien.

2. Mengevaluasi informasi, pengguna dapat mengevaluasi informasi secara kritis dan kompeten.

3. Menggunakan informasi, pengguna menerapkan atau menggunakan informasi secara akurat dan kreatif

Literasi informasi (melek informasi) menurut UNESCO (dalam Harjatanaya et al., 2018) merupakan keterampilan kognitif 
dalam membaca dan menulis yang tidak hanya terikat pada konteks sumber dan cara pemerolehan keterampilan tersebut. Keterampilan dalam mencari dan menggunakan informasi sangat diperlukan bagi seluruh civitas akademika karena perguruan tinggi merupakan tempat penyebaran dan perkembangan sebuah pengetahuan. Menurut Kurnianingsih, Rosini, \& Ismayati (2017) generasi digital native memiliki ketergantungan yang tinggi terhadap pencarian informasi di internet, tetapi tingkat literasi informasi di kalangan peserta didik berdampak masih rendah sehingga sering terjadi maraknya penjiplakan terhadap karya cipta.

Perancangan program literasi informasi menggunakan model literasi informasi. Pemilihan model literasi informasi disesuaikan dengan karakteristik pemustaka. Pada penelitian Baji dkk (2018) untuk membangun kemampuan literasi informasi untuk siswa tingkat sekolah dasar menggunakan model Big6. Selain itu, penelitian Dalton (2013) menggunakan model SCONUL Seven Pillars of Information Literacy untuk membangun kemampuan literasi informasi bagi praktisi bidang kesehatan. Sejalan dengan itu, Hess dan Greer (2016) merancang program literasi informasi untuk mahasiswa perguruan tinggi dengan menggunakan ADDIE Model.

Model literasi informasi yang dapat diterapkan pada berbagai jenis pemustaka. Perlu dilakukan analisis kebutuhan pemustaka, analisis karakteristik pemustaka dan kesiapan perpustakaan. Salah satu model literasi informasi yang cocok dimanfaatkan di pendidikan tinggi adalah model I-Learn. Pada penelitian yang dilakukan oleh Greenwell (2013) dikatakan bahwa perancangan desain instruksi menggunakan model I-Learn pada mahasiswa dapat meningkatkan kemampuan mahasiswa dalam menerima instruksi dan panduan perpustakaan digital. Menurut 
Neuman (2011) terdapat enam keahlian yang diperlukan dalam menggunakan informasi, yaitu:

1. Identifikasi (Identify) masalah informasi dengan memfokuskan pada minat, memperhatikan atau mengamati lingkungan sekitar, dan fokus pada pertanyaan

2. Menemukan (Locate) informasi yang dibutuhkan melalui pencarian dan penggalian informasi yang relevan.

3. Mengevaluasi (Evaluate) informasi tersebut dengan memperhatikan otoritas, relevansi, dan ketepatan waktunya.

4. Menerapkan (Apply) informasi tersebut sesuai dengan kebutuhan informasi.

5. Merefleksikan (Reflect) apa yang ditemukan dan merevisi sesuai kebutuhan

6. Mengetahui (kNow) apa saja yang telah dipelajari sehingga menyelesaikan masalah atau pertanyaan dan dapat digunakan untuk memacu generasi pengetahuan berikutnya.

Perpustakaan Universitas YARSI merupakan salah satu perpustakaan perguruan tinggi. Para mahasiswa dan civitas akademika Universitas YARSI sangat membutuhkan perpustakaan dalam menunjang proses belajar di perguruan tinggi. Perpustakaan sudah memiliki banyak koleksi dan fasilitas yang sangat mendukung kegiatan akademik. Dalam mendukung proses belajar, perpustakaan Universitas YARSI juga perlu memiliki program literasi informasi. Program ini membekali mahasiswa untuk dapat membuat tugas, membuat skripsi hingga mampu belajar sepanjang hayat. Selain itu dengan adanya program literasi informasi, mahasiswa juga mampu mengakses berbagai sumber informasi elektronik yang tersedia. Sehingga mahasiswa mampu 
menggunakan informasi yang benar, mengutip dengan benar dan mempresentasikannya dengan baik.

Perpustakaan Universitas YARSI memiliki kegiatan literasi informasi namun belum terjadwal dengan baik. Selain itu juga Perpustakaan Universitas YARSI pernah merancang kegiatan literasi informasi tetapi belum pernah terlaksana. Menurut Hafifah (2020) kegiatan literasi informasi yang dilakukan oleh pustakawan Perpustakaan Universitas YARSI adalah Problem Base Learning (PBL) yang terbatas pada mahasiswa Fakultas Kedokteran. Program ini diberikan pada mahasiswa untuk mempelajari bagaimana cara menelusur dan memanfaatkan sumber informasi elektronik. Sehingga program ini memiliki jangkauan yang sangat sedikit dari total sivitas akademika Universitas YARSI secara umum.

Universitas YARSI memiliki 6 Fakultas yaitu Fakultas Kedokteran, Fakultas Kedokteran Gigi, Fakultas Teknologi Informasi, Fakultas Ekonomi dan Bisnis, Fakultas Hukum, Fakultas Psikologi dan Sekolah Pascasarjana. Jumlah mahasiswa aktif Universitas YARSI pada tahun 2019-2020 berjumlah 5.931 orang. Berdasarkan data jumlah mahasiswa dengan pelaksanaan program literasi informasi masih sangat jauh dari harapan dalam mencapai tujuan pembelajaran sepanjang hayat. Kemampuan literasi informasi dibutuhkan oleh semua mahasiswa yang ada di Universitas YARSI. Hal ini bertujuan untuk membekali mahasiswa agar mandiri selama proses belajar.

Pembuatan program literasi informasi, diperlukan sebuah desain instruksional. Desain ini diperlukan untuk merumuskan kompetensi apa saja yang aka dicapai, materi apa yang akan diberikan, serta bagaimana uji kemampuan literasi informasi tersebut. Desain ini juga berisi tentang target yang akan dicapai oleh perpustakaan melalui kegiatan literasi informasi. Pembuatan desain ini harus disesuaikan dengan keadaan dan kebutuhan dari 
perpustakaan Universitas YARSI. Desain instruksional ini dibuat disesuaikan dengan kebutuhan dan karakteristik mahasiswa secara umum. Desain ini juga dibuat agar bisa diterapkan kepada mahasiswa baru, mahasiswa dalam proses belajar dan mahasiswa yang sedang mengerjakan tugas akhir. Berdasarkan latarbelakang konsep dan hasil observasi pada pelaksanaan kegiatan literasi informasi di Perpustakaan Universitas YARSI, diperlukan sebuah rancangan yang berisi desain intruksional program literasi informasi yang dapat diterapkan pada semua mahasiswa Universitas YARSI. Adapun desain instruksional dibuat berdasarkan pedoman model literasi informasi. Oleh karena itu dalam penelitian ini, desain instruksional untuk program literasi informasi yang dapat diterapkan di Perpustakaan Universitas YARSI.

\section{METODE}

Penelitian mengenai desain instruksional dilakukan dengan metode mix method. Metode kuantitatif dilakukan untuk mendapatkan gambaran secara umum karakteristik dan kebutuhan mahasiswa akan program literasi informasi. Metode kualitatif digunakan untuk mengetahui kesiapan perpustakaan dan pustakawan untuk melaksanakan program literasi informasi. Setelah data kuantitatif dan kualitatif dikumpulkan maka data tersebut menjadi dasar dalam membuat rancangan instruksional program literasi informasi. Untuk kemudian dibuatkan desain instruksional yang berisi penerapan model literasi informasi serta indikator yang digunakan selama pelaksanaan program. Adapun populasi dalam penelitian adalah pemustaka mahasiswa yang berkunjung ke perpustakaan selama bulan Februari 2020 sejumlah 3466 orang dari berbagai fakultas. Sehingga sampel berjumlah 359 orang mahasiswa. Teknik pengumpulan data primer dilakukan dengan kuesioner dan wawancara, serta didukung oleh data sekunder berupa observasi dan studi dokumentasi. 


\section{HASIL DAN PEMBAHASAN}

Mahasiswa membutuhkan beberapa langkah untuk memiliki kemampuan literasi informasi. Langkah disusun berdasarkan kebutuhan pemustaka kemudian dijadikan pedoman dalam menyusun desain instruksional. Model I-Learn menyediakan kerangka kerja untuk membantu mahasiswa belajar melalui penggunaan informasi (University of Kentucky, 2020). Adapun desain instruksional yang disusun untuk Perpustakaan Universitas YARSI adalah sebagai berikut:

\section{Identify}

Identifikasi merupakan tahap pertama pada model I-LEARN. Pada tahap ini, mahasiswa fokus pada memilih topik yang akan diselidiki, masalah yang akan dipecahkan, atau pertanyaan yang akan dijawab. Terdapat tiga tahapan dalam identifikasi, antara lain:

a. Activate, pada tahapan ini mahasiswa belajar untuk membangun rasa penasaran mereka terhadap suatu topik informasi.

b. Scan, pada tahapan ini mahasiswa dituntut untuk dapat menemukan topik yang sesuai dengan kebutuhan.

c. Formulate, tahapan dimana mahasiswa dapat membuat suatu pertanyaan atau merumuskan masalah pada suatu topik informasi.

Berdasarkan hasil data penelitian, kebutuhan informasi pengunjung perpustakaan Universitas YARSI adalah informasi mengenai akademik dengan persentase sebesar 35\% atau total 266 responden. Hal ini terjadi karena sebagian besar pengunjung merupakan mahasiswa yang sedang mencari sumber informasi baik untuk tugas perkuliahan dari dosen ataupun hanya sekedar ingin menambah wawasan bidang studinya. Dalam dunia perkuliahan, topik informasi biasanya didapatkan dari dosen yang 
mengajar. Baik berupa tugas, maupun materi perkuliahan. Selain itu, perpustakaan dapat turut andil dalam membuat pelatihan mind map atau sejenisnya agar dapat membantu mahasiswa dalam memetakan suatu topik informasi dan mengenali informasi yang dibutuhkan.

\section{Locate}

Lokasi akses informasi merupakan tahap untuk menemukan informasi pembelajaran, berfokus pada apa yang harus dipelajari, menemukan informasi yang terkait dengan pembelajaran tersebut, dan mengekstrak aspek yang paling relevan dan menonjol dari informasi itu untuk tugas belajar yang ada. Terdapat tiga tahapan pada proses locate, antara lain:

a. Focus, mahasiswa diharapkan dapat merinci dengan tepat mengenai informasi yang akan dipelajari.

b. Find, mahasiswa mampu untuk menemukan pilihan sumber informasi yang akan digunakan dalam pembelajaran.

c. Extract, mahasiswa dapat membuat daftar informasi yang paling relevan dan sesuai dengan kebutuhan informasi.

Berdasarkan hasil data penelitian, sebanyak $76.3 \%$ atau sekitar 280 responden memilih menggunakan internet untuk mengakses sumber informasi. Selain itu, media website juga dipilih sebagai lokasi mencari informasi yang dibutuhkan dengan jumlah persentase sebesar $65.7 \%$ atau sekitar 241 responden. Dari data tersebut, perpustakaan dapat membantu mengembangkan kemampuan literasi informasi dengan cara mengadakan seminar mengenai akses informasi, sumber informasi yang relevan, hingga subjek pencarian. Pelatihan pemanfaatan e-resources juga sangat diperlukan karena berdasarkan data analisis kebutuhan sebagian besar responden menggunakan internet untuk mencari sumber informasi. 


\section{Evaluate}

Evaluate atau evaluasi adalah tahapan atau proses yang paling penting dalam setiap tahapan literasi informasi. Pada tahapan ini, mahasiswa diharapkan dapat mengevaluasi informasi dan sumber-sumbernya secara kritis. Terdapat tiga tahapan pada proses evaluasi, antara lain:

a. Authority, mahasiswa belajar mengenai kredibilitas sumber informasi, kredibilitas penulis, dan keakuratan informasi.

b. Relevance, mahasiswa belajar untuk menyesuaikan informasi dengan kebutuhan informasi yang diperlukan.

c. Timeliness, mahasiswa belajar untuk dapat menggunakan informasi terbaru sesuai dengan perkembangan bidang ilmu.

Berdasarkan data penelitian, sebanyak 98 responden atau sekitar $27 \%$ tidak memperhatikan kredibilitas penulis pada saat mencari sumber informasi dan sebanyak 74 responden atau sekitar $20 \%$ masih memperhatikan informasi yang muncul paling atas pada mesin pencarian. Sekitar $40.3 \%$ atau sebanyak 148 responden masih menggunakan website komersial untuk mencari sumber informasi. Berdasarkan data tersebut, perpustakaan dapat turut andil dalam mengembangkan kemampuan literasi mahasiswa Universitas YARSI dengan cara mengadakan kegiatan atau pelatihan mengenai evaluasi informasi mulai dari mengetahui kredibilitas penulis, keakuratan suatu informasi, kesesuaian informasi dengan kebutuhan, hingga keterbaruan suatu informasi. Hal ini perlu menjadi perhatian karena informasi yang beredar melalui internet dan website sangat banyak dan beraneka ragam maka perlu adanya pengetahuan mendalam mengenai evaluasi informasi.

\section{Apply}

Penerapan merupakan tahapan pencarian informasi untuk pembelajaran dan menggunakan informasi untuk pembelajaran. 
Setelah melalui tahapan evaluasi informasi, selanjutnya mahasiswa harus mampu menerapkan informasi tersebut dalam pembelajaran. Terdapat tiga tahapan dalam proses apply, antara lain:

a. Generate, mahasiswa diharapkan mampu membangun pemahaman baru dari informasi yang telah didapat.

b. Organize, mahasiswa diharapkan mampu menentukan informasi yang akan digunakan dan menyusun kembali menjadi informasi baru.

c. Communicate, mahasiswa diharapkan untuk mampu menyampaikan dan menggunakan informasi menjadi produk baru sesuai dengan kebutuhan. Misalnya informasi tersebut digunakan untuk tugas perkuliahan, materi tambahan, dan lainnya.

Berdasarkan data penelitian, sekitar $46.6 \%$ atau sebanyak 171 responden menyatakan bahwa kurang mengerti cara mengutip informasi dalam karya tulis. Berdasarkan hal tersebut, perpustakaan dapat membuat program literasi informasi seperti kegiatan pelatihan cara pengutipan yang sesuai dengan standar agar mahasiswa dapat terhindar dari tindakan plagiarisme. Tidak hanya cara mengutip, sebagian responden juga kurang mengerti tentang cara membuat daftar pustaka secara otomatis. Sebanyak $46.3 \%$ atau 170 responden menyatakan bahwa kurang mengerti cara membuat daftar pustaka secara otomatis. Selain itu, sebanyak $65.1 \%$ atau sekitar 239 responden menyatakan bahwa tidak pernah menggunakan reference manager dalam membuat kutipan dan daftar pustaka.

Berdasarkan hal tersebut, perpustakaan Universitas YARSI dapat membuat program literasi informasi berupa pengenalan dan pelatihan menggunakan aplikasi reference manager yang dapat membantu mahasiswa dalam membuat kutipan dan daftar 
pustaka. Selain itu, perpustakaan Universitas YARSI juga dapat membuat pelatihan infografis karena berdasarkan data sebanyak 65.7\% atau sekitar 241 responden menggunakan media sosial dan website selain buku.

\section{Reflect}

Refleksi digunakan sebagai aplikasi pemikiran kritis untuk menilai proses dan produk pembelajaran sepanjang pengalaman pembelajaran. Terdapat tiga tahapan dalam proses refleksi, antara lain:

a. Analyze, mahasiswa diharapkan mampu melakukan analisis apakah bentuk produk yang diciptakan sudah sesuai dengan kebutuhan.

b. Revise, jika hasil akhir produk yang diciptakan terasa masih kurang, maka diharapkan mahasiswa dapat menambahkan atau memperbaikinya sesuai kebutuhan.

c. Refine, belajar untuk menilai kembali hasil produk yang telah diperbaiki.

Dalam tahapan ini, perpustakaan Universitas YARSI dapat menyediakan aplikasi plagiarism checker yang dapat digunakan oleh para mahasiswa. Mahasiswa dapat memanfaatkan layanan ini untuk tugas maupun tugas akhir mereka seperti skripsi dan tesis. Dengan adanya pemeriksaan tugas atau hasil karya mahasiswa dengan menggunakan aplikasi plagiarism checker dapat menuntut mahasiswa untuk selalu taat dalam standar pengutipan sehingga dapat mengurangi tingkat plagiarisme di lingkungan Universitas YARSI.

\section{Know}

Pada tahapan ini, mahasiswa dapat merepresentasikan kembali pengetahuan yang telah didapat. Bisa dalam bentuk tugas 
perkuliahan, jurnal, artikel, dan lainnya. Terdapat tiga tahapan dalam proses know, antara lain:

a. Internalize, mahasiswa belajar untuk dapat menghubungkan atau mengintegrasikan informasi tersebut dengan pengetahuan yang sebelumnya sudah didapat.

b. Personalize, mahasiswa mampu menciptakan makna baru sebagai suatu pengetahuan dalam diri.

c. Activate, mahasiswa dapat menggunakan pengetahuan atau informasi tersebut sesuai dengan kebutuhannya.

Peran perpustakaan dalam memanfaatkan program literasi antara lain dengan cara mengenalkan jurnal-jurnal yg dapat digunakan oleh mahasiswa sebagai wadah publikasi karyanya. Tidak hanya jurnal, media online seperti portal berita bahkan koran pun dapat dijadikan sebagai sarana publikasi. Berdasarkan hasil data penelitian, sebanyak 58 responden atau sekitar 15.3\% masih memilih Scopus sebagai salah satu sumber informasi. Padahal seperti yang kita ketahui, Scopus merupakan alat indeks jurnal yang berguna untuk para peneliti bisa mengukur dan menentukan dimana akan menerbitkan jurnal atau artikel ilmiahnya.

Berikut ini adalah ringkasan desain instruksional program literasi informasi yang sesuai dengan Perpustakaan Universitas YARSI dengan menggunakan model I-LEARN:

Tabel 1. Desain Instruksional Program Literasi Informasi Perpustakaan Universitas YARSI menggunakan I-Learn Model

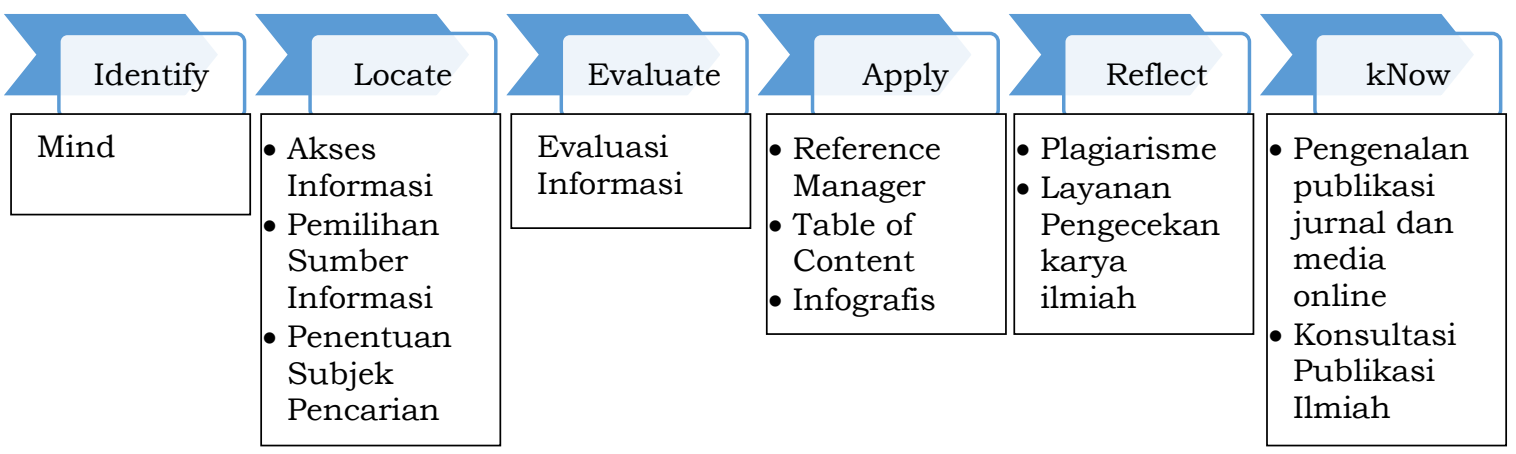




\section{PENUTUP}

Program literasi informasi merupakan salah satu upaya meningkatkan keterampilan individu dalam mencari informasi yang dibutuhkannya. Pada perpustakaan perguruan tinggi, adanya program literasi informasi dapat membantu sebagai penunjang pelaksanaan program yang sesuai dengan Tri Dharma perguruan tinggi. Desain instruksional program literasi informasi untuk Perpustakaan Universitas YARSI menggunakan model ILearn terdiri dari identify, locate, evaluate, apply, reflect, dan know. Program yang dibuat disesuaikan dengan kebutuhan dan karakteristik mahasiswa secara umum dan sivitas akademika secara khusus. Perpustakaan Universitas YARSI perlu memiliki program literasi informasi yang diperlukan oleh semua mahasiswa. Selain itu, perpustakaan Universitas YARSI disarankan untuk dapat mengembangkan program literasi informasi secara spesifik sesuai dengan kebutuhan informasi masing-masing program studi. 


\section{DAFTAR PUSTAKA}

Baji, F. et al. (2018) 'Developing information literacy skills of the 6 th grade students using the Big6 model', Malaysian Journal of Library \& Information Science, 23(1), pp. 1-15. doi: 10.22452/mjlis.vol23no1.1.

Dalton, M. (2013) 'Developing an evidence-based practice healthcare lens for the SCONUL Seven Pillars of Information Literacy model', Journal of Information Literacy, 7(1), pp. 30-43. doi: 10.11645/7.1.1813.

Greenwell, S. C. (2013). Using the I-LEARN model for information literacy instruction: An Experimental Study. ProQuest Dissertations and Theses, 106. Retrieved from https:/ / uknowledge.uky.edu/cgi/viewcontent.cgi?article=1005 \&context=edc_etds

Harjatanaya, T. Y., Islamy, G. C. S., Damayanti, I. L., Fadlan, Susanti, D. R., Yuliati, ... Wina. (2018). White Paper : Literasi di Indonesia Divisi Kajian Komisi Pendidikan PPI Dunia 2017/2018. Retrieved from http://ppidunia.org/wpcontent/uploads/2018/11/White-Paper-Komisi-PendidikanPendidikan-Literasi.pdf \%0A

Hafifah, F.R. (2020). Rancangan Program Literasi Informasi Menggunakan Model I-Learn Untuk Perpustakaan Universitas YARSI. Skripsi. Universitas YARSI

Hess, A. K. N. and Greer, K. (2016) 'Designing for Engagement: Using the ADDIE Model to Integrate High-Impact Practices into an Online Information Literacy Course', Communications in Information Literacy, 10(2), pp. 264-282. doi: 10.15760/comminfolit.2016.10.2.27.

Mubasyaroh. (2016) 'Pengaruh Perpustakaan Bagi Peningkatan Mutu Pendidikan Perguruan Tinggi, Libraria, 4(1), pp 77-104.

Lau, J. (2006). Guidelines on Information Literacy for Lifelong Learning. International Federation of Library Associations and Institutions. Retrieved from https://www.ifla.org/files/assets/informationliteracy/publications/ifla-guidelines-en.pdf

Neuman, D. (2011). Constructing knowledge in the twenty-first century: I-LEARN and using information as a tool for learning. School Library Media Research, 14(August). Retrieved from http: / / www.ala.org/aasl/sites /ala.org.aasl/files / content/aaslp ubsandjournals/slr/vol14/SLR_ConstructingKnowledge_V14.p df

Kurnianingsih, I., Rosini, R., \& Ismayati, N. (2017). Upaya Peningkatan Kemampuan Literasi Digital Bagi Tenaga Perpustakaan Sekolah dan Guru di Wilayah Jakarta Pusat Melalui Pelatihan Literasi Informasi. Jurnal Pengabdian Kepada Masyarakat (Indonesian Journal of Community Engagement), 3(1), 61-76. https:/ / doi.org/10.22146/jpkm.25370 
Unesco. (2007) 'Understanding Information Literacy: A Primer'. Paris. Unesco

University of Kentucky. (2020). The I-LEARN Model: Introduction. Retrieved April 26, 2020, from https://libguides.uky.edu/ilearn 